\title{
ANALISIS INSTRUMEN KENDANG DALAM KARAWITAN JAWA DI TINJAU DARI NILAI LUHUR TAMANSISWA
}

\author{
Arya Dani Setyawan ${ }^{1}$, Ardian Arief ${ }^{2}$, Akbar Al Masjid $^{3}$ \\ I, 2, 3 Pendidikan Guru Sekolah Dasar Universitas Sarjanawiyata Tamansiswa Yogyakarta \\ Iaryadanisetyawan@gmail.com \\ 2ardian.arief@ustjogja.ac.id
}

3almasjida@ustjogja.ac.id

\section{Informasi artikel}

Sejarah artikel

Diterima

$: 15 / 10$

Revisi : 20

Dipublikasikan : 28/12/2107

Kata kunci:

Analisis estetika,

karawitan Jawa,

nilai luhur Tamansiswa \begin{abstract}
ABSTRAK
Penelitian ini bertujuan mendeskripsikan analisis estetika karawitan Jawa dalam kaitannya dengan nilai-nilai luhur Tamansiswa. Penelitian ini menggunakan metode penelitian kualitatif dengan pendekatan studi kasus yaitu mengamati secara langsung ke lapangan dengan melakukan wawancara kepada pelaku seni, lembaga, dan masyarakat sekitar. Hasil wawancara digunakan untuk memperoleh informasi tentang kekuatan, kelemahan, peluang, dan hambatan dari masing-masing kelompok karawitan yang ada dilingkungan Tamansiswa. Hasil wawancara di analisis menggunakan analisis SWOT kemudian dipetakan dengan matriks EFAS dan IFAS. Tujuan akhir dari penelitian ini adalah merumuskan strategi analisis estetika pada karawitan jawa yang berada di Yogyakarta dan khususnya berada di lingkungan Tamansiswa. Gamelan dan Tamansiswa menjadi satu kesatuan estetika karena nilai yang terkandung dalam gamelan itu sendiri erat dengan ajaran Tamansiswa yaitu Tri Saksi Jiwa (Cipta, Rasa, Karsa) cipta selalu terkait dengan bentuk instrument gamelan sedangkan rasa adalah manifestasi dari hasil yang di bunyikan dari gamelan kemudian karsa adalah ciri khas kebudayaan yang meliputi kekuatan gotong-royong (kebersamaan) dalam menyajikan pertunjukan gamelan.
\end{abstract}

Keyword:

Aesthetic analysis,

Javanese karawitan,

noble value Tamansiswa

\section{ABSTRACT}

This study aims to describe the aesthetic analysis of Javanese Karawitan in relation to noble values Tamansiswa. This research uses qualitative research methods with a case study approach that is observing directly to the field by conducting interviews to artists, institutions, and the surrounding community. Interview results are used to obtain information about the strengths, weaknesses, opportunities, and obstacles of each karawitan groups that exist in Tamansiswa. The result of interview in analysis using SWOT analysis then mapped with EFAS and IFAS matrix. Gamelan and Tamansiswa become a unity of aesthetics because the value contained in the Gamelan itself is closely related to the teachings of Tamansiswa Tri Saksi Jiwa (Cipta, Rasa, Karsa) Cipta is always associated with the form of Gamelan instruments. While Pain is a manifestation of the sounds of gamelan. Then Karsa is a cultural characteristic that includes the power of mutual cooperation (togetherness) in presenting gamelan performances.

\section{Pendahuluan}

Gamelan jawa merupakan kumpulan dari instrument tradisional yang masih ada dan berkembang di tanah jawa. Gamelan kehadiranya membawa beberapa dampak yang signifikan bagi perkembangan seni budaya Indonesia. Secara filosofis gamelan jawa merupakan satu bagian yang tak terpisahkan dari kehidupan masyarakat 
Jawa. Hal demikian disebabkan falsafah hidup masyarakat Jawa berkaitan dengan seni budayanya yang berupa gamelan Jawa serta berhubungan dekat dengan perkembangan religi yang dianutnya. Bagi masyarakat Jawa gamelan mempunyai fungsi estetika yang berkaitan dengan nilai-nilai sosial, moral dan spiritual. Dalam suasana bagaimanapun suara gamelan mendapat tempat di hati masyarakat (Purwadi, 2006:26). Gamelan dapat digunakan untuk mendidik rasa keindahan seseorang. Pemahaman melalui gamelan dapat mengajarkan arti penting etika dan estetika kehidupan. Contohnya adalah secara visual gamelan dapat dilihat melalui bentuk rancak yang indah, warna yang sangat khas, dan faktor pendukung lain seperti bentuk pencon dan bilah yang menyatu. Hal tersebut sangat beralasan bahwa leluhur menciptakan gamelan dengan nilai-nilai adiluhung.

Duniapun mengakui bahwa gamelan adalah alat musik tradisional timur yang dapat mengimbangi alat musik barat yang serba besar. Budaya Jawa mulai terkikis dan jauh dari pewarisnya. Hal tersebut terjadi, lantaran sebuah peninggalan adiluhung peninggalan leluhur kurang diajarkan pada anak-anak usia dini, sehingga mereka lebih asyik dengan permainan modern yang notabene bukan ciri khas budaya dari negeri sendiri. Orang yang biasa berkecimpung dalam dunia karawitan, rasa kesetiakawanan tumbuh, tegur sapa halus, tingkah laku sopan. Ditinjau dari instrumenya saja gamelan mengajarkan tentang perbedaan tetapi kalau perbedaan tersebut dapat disatukan dan di tabuh/disajikan secara bersama-sama akan menghasilkan suara yang harmoni. Namun demikian harmoni terbentuk juga berdasarkan ritme, irama, melodi, dan laya yang dihasilkan dari masing-masing instrument (Rahayu Supanggah, 2009:229). Secara audio visual dampak dari tabuhan gamelan yang bisa juga disebut karawitan dapat memberikan keindahan terhadap penikmatnya. Estetika yang terkandung dalam gamelan jawa menjadi bahan kajian untuk selalu diamati dan diteliti setiap bagianya.

Tamansiswa yang menjadi salah satu pelestari kebudayaan turut memberikan kontribusi dalam hal pengembangan kesenian tradisioanl khususnya gamelan. Konsep tersebut terilhami dari Ki Hadjar Dewantara dengan nasehatnya bahwa kebudayaan adalah buah budi yang mengandung sifat-sifat luhur dan indah, sebagai hasil perjuangan hidup manusia terhadap kekuatan alam dan zaman yang berlangsung terus menerus sepanjang hidup manusia (Tim Tamansiswa, 2012:36). Konsep keindahan dalam kebudayaan tersebut dapat dijabarkan melalui gamelan dengan berbagai aspek yang dapat dilihat keindahanya. Semakin majunya arus teknologi memicu manusia untuk berpikir instan dengan berbagai alasan. Degradasi makna pada gamelan jawa turut memberikan pengaruh terhadap pengembangan pola pikir manusia. Oleh karena itu peneliti mempunyai gagasan untuk mengkaji lebih dalam pemahaman estetika pada gamelan jawa. Keindahan pada gamelan tidak hanya terpusat pada faktor visualnya tetapi dapat berpengaruh terhadap suaranya.

Berdasarkan permasalahan diatas peneliti tertarik untuk melakukan penelitian "Analisis Estetika Karawitan Jawa Ditinjau Dari Nilai Luhur Tamansiswa”

\section{Metode Penelitian}

Penelitian ini menggunakan pendekatan kualitatif. Pendekatan kualitatif mampu menghasilkan uraian yang mendalam tentang ucapan, tulisan, dan perilaku yang dapat diamati dari suatu individu, kelompok, masyarakat, atau organisasi tertentu dalam suatu setting konteks yang dikaji dari sudut pandang yang utuh, komprehensif, dan holistic (Sutopo, 2002:I I I). Selanjutnya metode yang digunakan yakni studi kasus. Penggunaan studi kasus untuk memperoleh data dari berbagai sumber investigasi dokumen, arsip, wawancara, observasi, artifak, sumber lainya secara sistematik terhadap individu, kelompok, organisasi atau kegiatan (event). Studi kasus dapat digunakan untuk memperoleh pemahaman uraian-uraian gambaran dan memperoleh penjelasan dari suatu fenomena secara menyeluruh.

Teknik pengumpulan data menggunakan observasi, wawancara, Focus group discussion. Kemudian teknik analisis data yang digunakan analisis SWOT (Strengths, Weakness, Opportunities, threats). 


\section{Hasil Penelitian dan Pembahasan}

\section{Konsep Gamelan Jawa}

Proses penciptaan dalam karawitan adalah suatu tindakan, pembuatan atau pengolahan yang bertujuan untuk menciptakan sebuah karya berbentuk komposisi gending. Menurut Irving Tylor yang dikutip oleh Marsudi (1998: 36) menjelaskan, bahwa proses kreatif terdiri dari empat tingkat dasar meliputi keterbukaan, inkubasi, iluminasi (penerangan) dan eksekusi (pelaksanaan).

Garap karawitan dalam perkembangannya dapat dianggap telah mengalami kemajuan yang cukup pesat. Hasil pengembangan yang telah dilakukan, yaitu berupa karya-karya baru karawitan menjadi sebuah bukti, bahwa unsur dan faktor pendukung lainnya dapat menghasilkan karya musikal yang lebih dinamis dan menarik. Terciptanya karya baru sekaligus merupakan bukti, bahwa karawitan telah mendapatkan posisi yang tepat, bukan hanya sebagai sebuah musik yang diperdengarkan sebagai pengisi waktu atau suasana, tetapi juga mampu berdiri sebagai sebuah pertunjukan yang sangat perlu mendapatkan perhatian secara serius seperti jenis seni pertunjukan lainnya. Tahapan ini dapat dicapai dengan proses kreatif dan perjuangan yang panjang dari para seniman dan pemikirnya. Latar belakang penciptaan gending juga banyak digagas dari kehidupan sehari-hari, misalnya peringatan atas sebuah peristiwa penting, faktor kejenuhan dari para pelaku seni, sarana ibadah, relaksasi, dan lain sebagainya. Beberapa pemikiran dari gagasan tersebut dituangkan ke dalam ide kemudian diwujudkan melalui media karya seni dan disusun sebagai sebuah gending yang terstuktur dengan baik.

\section{Estetika Gamelan Jawa}

Kebudayaan adalah keseluruhan sistem gagasan, tindakan, dan hasil karya manusia dalam rangka kehidupan masyarakat yang dijadikan milik diri manusia dengan belajar. Kebudayaan dapat dibagi menjadi tujuh unsur, yang salah satunya adalah kesenian. Seni atau kesenian merupakan salah satu unsur kebudayan yang universal. Seni merupakan keahlian manusia dalam karyanya yang bermutu, dilihat dari segi kehalusan atau keindahan. Setiap bangsa, suku bangsa bahkan setiap diri manusia mempunyai seni (Koentjaraningrat, 2009: I44).

Demikian pula dengan Indonesia yang dihuni oleh ratusan suku bangsa, mempunyai kesenian yang tentunya beraneka ragam. Jawa sebagai salah satu suku yang relatif besar di Indonesia memiliki juga kesenian yang beraneka ragam. Hal itu bisa dilihat dari banyaknya hasil karya suku tersebut yang masih dapat bertahan hingga sekarang, misalnya tari tradisional, seni wayang kulit, wayang orang, kethoprak, dan lain sebagainya. Seni atau kesenian yang sudah lama dikenal oleh masyarakat sering kali disebut tradisional. Artinya kesenian seperti itu sudah ada sejak dahulu dan diwariskan kepada generasi mudanya sampai sekarang.

\section{Estetika Garap Gending dalam Karawitan}

Garap dalam bahasa sehari-hari mempunyai arti mengerjakan ataupun menyelesaikan sesuatu. Dalam bahasa Jawa nggarap digunakan sebagai kata kerja untuk menunjukkan kerja seseorang dengan harapan akan mendapatkan hasil. Sebagai contoh kata nggarap dapat diaplikasikan sebagai bentuk kata kerja misalnya "pak tani lagi nggarap sawah" (pak tani sedang menggarap sawah) berarti mengerjakan segala sesuatu yang berkaitan dengan proses persiapan penanaman padi di sawah termasuk membajak, mencangkul, dan memupuk dengan harapan agar padi dapat dipanen dengan hasil yang memuaskan. Apabila dihubungkan kata kerja nggarap atau garap ke dalam dunia karawitan dapat diartikan mengolah dan mengerjakan segala sesuatu yang berkaitan dengan sebuah karya komposisi gending, agar menjadi sebuah penyajian yang mempunyai nilai keindahan.

Salah satu aspek yang mempengaruhi garap antara lain gending dan ricikan pendukungnya. Garap dalam hal ini juga memberikan kontribusi untuk memilahkan kelompok instrumen berdasarkan peran serta tingkat kesulitan di dalam perangkat gamelan. Kelompok instrumen yang dimaksud adalah instrumen garap ngajeng dan garap wingking. 
Garap ngajeng mempunyai pengertian instrumen gamelan dengan tingkat kesulitan tertentu. Pola permainan dari instrumen ini mempunyai banyak lagu ritmis maupun melodis, dalam dunia karawitan lazim disebut cengkok, sekaran dan wiled. Seorang pengrawit yang menginginkan untuk memposisikan diri sebagai penabuh garap ngajeng harus mencapai tingkatan kemampuan dan keterampilan. Instrumen yang termasuk garap ngajeng adalah kendang, rebab, gender, gambang, suling, bonang dan siter.

Pengertian garap wingking adalah cara memainkan instrumen dengan pola tertentu yang hampir sama dengan garap balungan. Instrumen pendukung yang masuk dalam kategori garap wingking meliputi Slentem, Demung, Saron, Peking dan Bonang Panembung. Garap wingking mempunyai peran penting pada tabuhan garap soran, sebab balungan mempunyai tugas untuk membawakan melodi baku.

Istilah garap dapat berarti interpretasi, yang melibatkan kebebasan improvisasi pengrawit dan penafsiran yang dituangkan dalam sebuah komposisi gending. Setiap pengrawit mempunyai kemampuan berbeda dalam menafsirkan garap karena banyak faktor yang melatarbelakangi, misalnya kemampuan, keterampilan dan cara mengapresiasi suatu bentuk balungan untuk kemudian ditafsirkan dalam garap cengkok maupun wiledan.

\section{Gamelan Jawa dan Nilai Luhur Tamansiswa}

Nilai-nilai luhur Tamansiswa merupak nilai yang diwariskan dari ajaran Ki Hadjar Dewantaran bersama rekan-rekan yang membawa pesan dan karakter luhur, sehigga dapt menjadi tonggak acuan berperilaku dalam beberbagai tindakan kehidupan. Nilai-nilai luhur tamansiswa menurut Tim Tamansiswa yang mengarah dalam kegiatan ekstrakurikuler karawitan antara lain adalah sebagai berikut.

a. Tri Saksi Jiwa (Cipta, Rasa, dan Karsa)

Cipta adalah akal fikiran manusia atau semua yang bisa ditangkap oleh panca indera sehingga bentuk dan visualisasinya jelas. Rasa adalah hati nurani yang mengendalikan semua perasaan manusia seperti marah, sedih, gembira, semangat, lesu dan sebagainya. Karsa adalah keinginan atau bagian yang menggerakkan manusia untuk mencapai keinginannya

b. Tri Nga (Ngerti, Ngroso, Nglakoni)

Ngerti, Ngroso, nglakoni artinya adalah pertama, Ngerti yaitu mengetahui ilmu apa yang diperoleh (kognitif). Kedua, Ngrasa yaitumerasakan atau menjalankan ilmu yang didapatnya tercermin dari sikap yang dilakukan (afektif). Ketiga, Nglakoni yaitu melaksanakan atau mempraktikan ilmu yang didapatnya (psikomotor).

\section{c. Tri N (Niteni, Nirokke, Nambahi)}

Pertama, Niteni yaitu memahami apa yang didapat disekelilingnya. Kedua, Nirokke yaitu menirukan hal positif yang didapatnya. Ketiga, Nambahi yaitu menambahkan apa yang dilakukan agar lebih baik lagi. Jadi dari proses niteni, nirokke dan nambahi merupakan proses alamiah yang pasti dilakukan oleh semua manusia tanpa kita sadari sebelumnya.

\section{d. Ning - Neng - Nung - Nang}

Ning yaitu melakukan sesuatu pekerjaan atau tindakan dengan fikiran yang hening. Neng berasal dari kata meneng, yang artinya tidak mudah emosi. Melakukan sesuatu pekerjaan atau tindakan dengan tidak mudah emosi. Nung berasal dari kata hanung, yang artinya teguh, kuat, dan sentosa.. Nang berasal dari kata menang, yang artinya wewenang atau tanggung jawab. Dengan demikian nang adalah tindakan yang dilakukan dengan penuh rasa tanggung jawab. 


\section{e. Ngandel - Kendel - Bandel - Kandel}

Pertama, Ngandel yaitu percaya kepada Tuhan dan percaya pada diri. Kedua, Kendel yaitu berani berkata atau bertindak karena hal tersebut benar. Ketiga, Bandel yaitu tahan bantingan atau dengan kata lain tidak mudah putus asa. Keempat, Kandel yaitu tebal kepercayaannya atau tebal imannya.

\section{Analisis Estetika Instrument Kendang Pada Gamelan Jawa}

Estetika merupakan bagian penting dari disiplin ilmu filsafat, yang hakekatnya telah menempatkan pola-pola dikotomis antara realitas dan abstraksi, dan juga antara keindahan dan makna yang sesungguhnya. Estetika dalam hal ini tidak lagi membahas tentang keindahan dalam pengertian konfensional, tetapi telah bergeser dalam sebuah wacana dan fenomena. Estetika dari suatu hasil karya seni modern jika dipahami melalui pemahaman filsafat seni yang merujuk pada konsep-konsep keindahan jaman Yunani (abad pertengahan), akan mengalami beberapa persempitan, degradasi bahkan pembunuhan preseptual, berdasarkan para ahli pemahaman estetika bukan hanya sebuah simbolisai dan makna, akan tetapi termasuk dalam kategori daya pada setiap perspektifnya. Dalam hal pemahaman pemaknaan dan ekspresinya bentuk daripada seni tersebut apapun bentuk dan media pengungkapannya pada dasarnya adalah ungkapan dan curahan estetik oleh seniman.

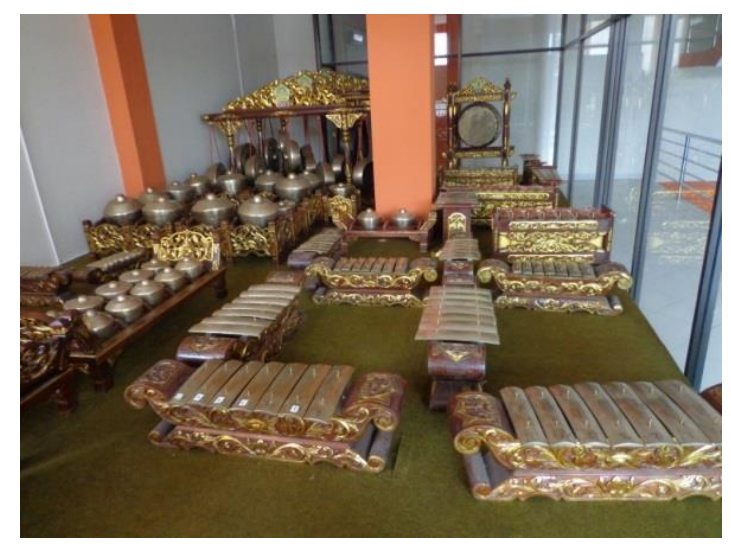

Gambar I. Dokumentasi Gamelan Ageng

Contoh gambar diatas merupakan jenis gamelan ageng yang secara estetika bentuk mengaju kepada pola yang terdapat dalam lingkungan sosial masyarakat jawa. Gamelan tidak bisa lepas dari kebersamaan oleh karena itu gamelan mempunyai sifat sosial. Dalam tata cara menabuh gamelan juga mempunyai peraturan tersendiri. Artinya apabila dilihat pada aspek fisiknya gamelan dapat menggambarkan tentang keberagaman bentuk tetapi tetap harmoni dalam satu kesatuan. Apabila dilihat dari aspek bentuk dan bahanya bakunya, gamelan mempunyai banyak sekali jenis dari yang terbuat dari kayu, bambu, kulit, tembaga, perunggu, dan lain sebagainya. Dari beberapa contoh jenis bahan baku tersebut masing-masing mempunyai peran yang berbeda. Secara estetis bahwa jenis bahan yang digunakan untuk membuat gamelan mempunyai peran dan fungi tertentu. Berikut ini adalah klasifikasi bahan baku apabila ditinjau dari estetika pembuatanya

a. Instrumen yang terbuat dari kulit

Dalam ansambel gamelan terdapat beberapa instrument yang terbuat dari kulit diantaranya adalah instrumen kendang, rebab, dan bedug. Instrument kendang dalam karawitan mempunyai fungsi utama sebagai pengatur lagu. Peran kendang yang sedemikian rupa dalam ansambel menyebabkan instrument ini mendapat porsi utama dalam pertunjukan. Apabila dikaji kembali dalam aspek estetika bentuk kendang memiliki tiga jenis ukuran dimulai dari yang paling kecil (ketipung), sedang (batangan), besar (bem atau ageng). Secara filosofi perwujudan dari kendang tersebut mempunyai fungsi masing-masing. Dalam pertunjukanya kendang ketipung mempunyai karakter dinamis sehingga apabila ada gending 
yang sifatnya dinamis kendang ketipung menjadi pemimpinya adapun jenis gending yang menggunakan kendang ketipung adalah lancaran, ladrang, ketawang, serta lagu dolanan.

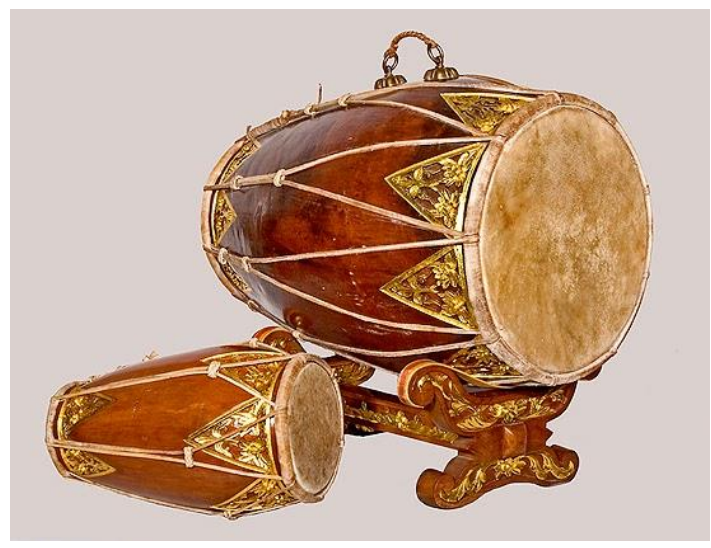

Gambar 2. Instrumen Kendang Ketipung

Warna suara dari instrument ini membuat kendang ketipung menjadi salah satu instrument atraktif pada suatu gending dalam karawitan atau gamelan jawa.

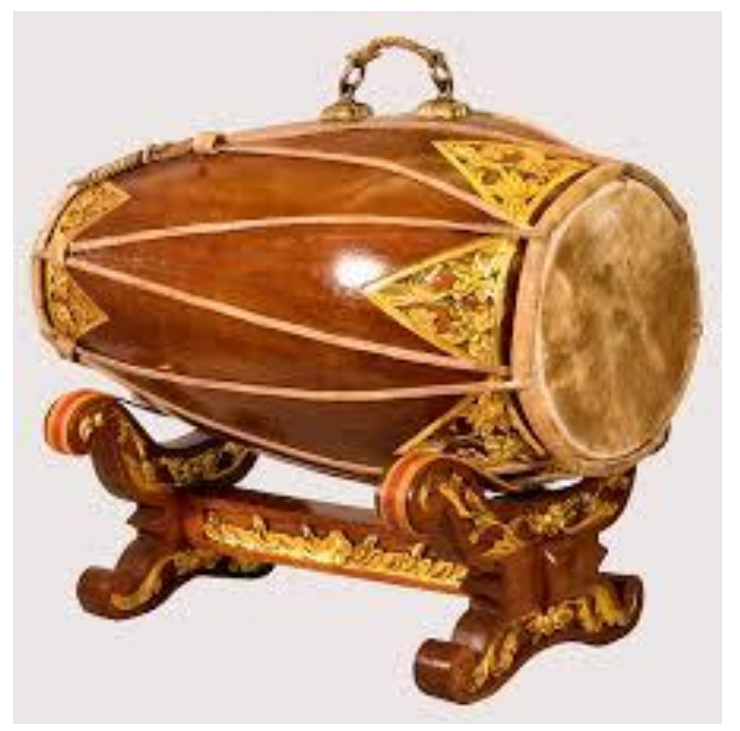

Gambar 3. Instrumen Kendang Batangan

Selanjutnya adalah kendang batangan atau biasa disebut kendang ciblon. Kendang batangan dalam karawitan berfungsi sebagai pengatur irama dan penentu sebuah tafsir, hakekatnya pada pola gerak tarian dan pertunjukkan yang lainya. Peran kendang batangan dalam ansambel gamelan sangat penting sekali karena harus mampu memimpin dari berbagai macam instrument yang ada pada gamelan. Pertunjukan karawitan sendiri dibagi menjadi 2 aspek yaitu karawitan sebagai pertunjukan mandiri dan karawitan sebagai iringan.

Peran kendang batangan pada pertunjukan karawitan mandiri adalah sebagai penghias irama, karena berdasarkan pertunjukanya karawitan mandiri dapat mampu menentuukan alur sesuai dengan keindahan dinamika gending atau lagu yang disajikan. Adapun peran kendang dalam iringan maksudnya adalah kendang dapat memimpin karawitan dalam hal gerak dan aspek pendukung lainya. Sebagai contoh dalam pertunjukan tari ramayana peran kendang batangan adalah sebagai ilustrasi untuk mengikuti gerak tari tersebut, karena setiap ragam gerak tari menggunakan unsur dan irama yang berbeda. Karena dalam pertunjukan tari ramayana banyak sekali adegan yang membutuhkan dinamika 
iringan sehingga kendang batangan bertugas sebagai pengatur dinamika jalanya pertunjukan. Sebagai contoh peran kendang batangan pada adegan yang membutuhkan tekanan dan ilustrasi serta penekanan pada tiap geraknya.

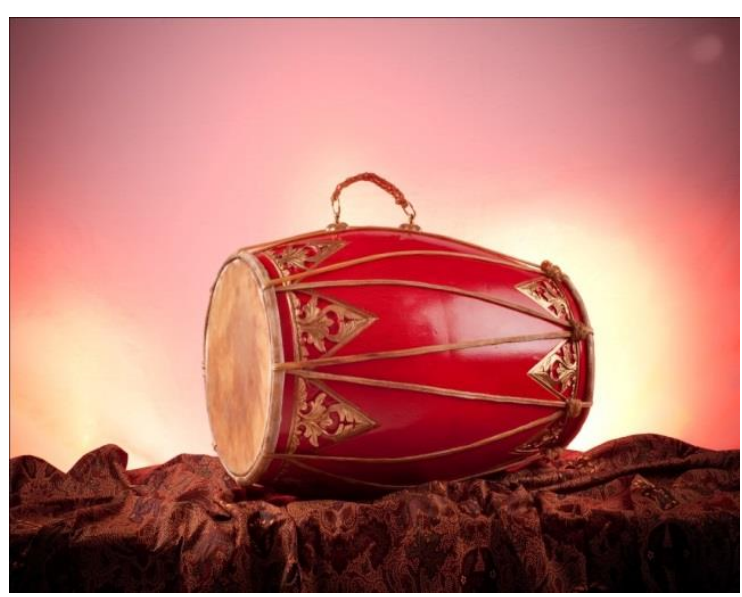

Gambar 3. Instrumen Kendang Ageng

Jenis kendang yang ketiga adalah kendang ageng atau bem, kendang ini mempunyai ukuran paling besar sendiri diantara ketiga jenis kendang. Secara estetika kendang ageng mempunyai tingkat kerumitan dalam membuatnya karena selain tampilan diluar yang menggunakan pola ukir-ukiran pada bagian dalam kendang juga terdapat ruang resonator bunyi. Bagian resonator pada kendang berfungsi untuk mengatur bunyi yang diseuaikan dengan karakter dari dan ukuran kendang tersebut. Bagian unik lai dari kendang ageng adalah pada tebokan kulit yang melapisinya, karakter dari kendang ini adalah menep, sareh, dan mantep. Dalam pertunjukan karawitan kendang ageng ini berfungsi untuk memimpin karakter gending yang agung dan berwibawa. Secara estetika bentuk dari kendang ini sesuai dengan ukuran selalu bertanggung jawab pada jenis gendig atau lagu yang sifatnya agung dan berat.

\section{Kesimpulan}

Gamelan dan Tamansiswa adalah dua unsur yang berkait menyatu serta tidak bisa dilepaskan. Terkait dengan beberapa ajaran Tamansiswa konsep Tri Saksi Jiwa meliputi Cipta Rasa dan Karsa menjadi sebuah keberlanjutan dari manifestasi perjalanan Tamansiswa itu sendiri. Pedoman Cipta pada konsep diatas membawahi gamelan dengan pola nyata dari instrument termasuk bentuk fisik dan jenis instrumentnya, cipta merupakan konsep keindahan yang di ilhami dengan bentuk instrument gamelan. Sedangkan rasa adalah bagimana gamelan di tabuh atau dibunyikan

\section{Referensi}

Hari Sulastyanto. 2007. Seni dan Budaya. Bandung: Grafindo Media Pratama.

Koentjaraningrat. 1985. Kabudayaan Mentalitas dan Pembangunan. Jakarta: PT Gramedia.

Koentjaraningrat. 2002. Pengantar Ilmu Antropologi. Jakarta: Rineka Cipta.

Junaidi Ghoni. 2012. Metodologi Penelitian Kualitatif. Yogyakarta: Ar-Ruzz Media,.

Suwardi Endrasmara. 2006. Penelitian Kebudayaan Ideologi, Epistimologi, dan Aplikasi. Tangerang: PT Agromedia Pustaka,

Karl Edmond Prier, Sj,. 1987. Kula Sowan Gusti: Kumpulan Gending Gereja Karangan C. Hardjasoebrata. Yogyakarta: Pusat Musik Liturgi. 
Marsudi. 1998. "Ciri Khas Gending-gending Ki Nartosabdo: Satu Kajian Aspek Musikologi dalam Karawitan”, Tesis sebagai salah satu syarat untuk mencapai derajat sarjana S-2 Universitas Gadjah Mada Yogyakarta.

Moh Roqib. 2007. Harmoni Dalam Budaya Jawa. Purwokerto: STAIN Purwokerto Press.

Koentjaraningrat. 2009. Pengantar Ilmu Antropologi. Jakarta: Rineka Cipta.

Rahayu Supanggah. 2009. Bothekan Karawitan II. Surakarta: ISI Press.

Subuh. 2006. Gamelan Jawa Inkulturasi musik Gereja. Surakarta : STSI Press.

Sutopo. 2002. Metodologi Penelitian Kualitatif Dasar, Teori, dan Terapannnya dalam Penelitian. Surakarta: UNS Press.

Tim Tamansiswa. 2012. Tamansiswa (Badan Perjuangan Kebudayaan \& Pembangunan Masyarakat). Yogyakarta: Perguruan Tamansiswa 